\title{
Diabetes and hepatocellular carcinoma risks in patients with nonalcoholic steatohepatitis related cirrhosis
}

\author{
Chien-Hsieh Chiang ${ }^{1,2,3}$, Kuo-Chin Huang ${ }^{1,4}$ \\ ${ }^{1}$ Department of Family Medicine, National Taiwan University Hospital \& College of Medicine, Taipei; ${ }^{2}$ Department of Community and Family \\ Medicine, National Taiwan University Hospital Yunlin Branch, Yunlin; ${ }^{3}$ Graduate Institute of Pharmacology, National Taiwan University College of \\ Medicine, Taipei; ${ }^{4}$ Hepatitis Research Center, National Taiwan University Hospital, Taipei \\ Correspondence to: Kuo-Chin Huang, MD, PhD. Professor, Department of Family Medicine, National Taiwan University Hospital, 7, Chung Shan \\ South Road, Taipei. Email: bretthuang@ntu.edu.tw. \\ Provenance and Peer Review: This article was commissioned by the editorial office, Hepatobiliary Surgery and Nutrition. The article did not undergo \\ external peer review. \\ Comment on: Yang JD, Ahmed F, Mara KC, et al. Diabetes is Associated with Increased Risk of Hepatocellular Carcinoma in Cirrhosis Patients with \\ Nonalcoholic Fatty Liver Disease. Hepatology 2020;71:907-16.
}

Submitted Oct 21, 2019. Accepted for publication Nov 28, 2019.

doi: 10.21037/hbsn.2019.11.03

View this article at: http://dx.doi.org/10.21037/hbsn.2019.11.03

Hepatocellular carcinoma (HCC) oncogenesis in the absence of alcoholic liver disease and chronic viral hepatitis has aroused growing clinical concern in clinical practice. In the era of remarkable advances of viral hepatitis treatment, nonalcoholic steatohepatitis (NASH) has become an emerging cause of $\mathrm{HCC}(1,2)$. Diabetes is a major risk factor of NASH and nonalcoholic fatty liver disease (3). With the increasing burden of diabetes globally, diabetes has also been recognized for contributing to cirrhosis, HCC development, and deaths from HCC (4-6). Nonetheless, the role of diabetes in the progression of NASH-related cirrhosis to HCC is unclear.

To investigate the link between risk of HCC and diabetes among patients with NASH-related cirrhosis, Yang et al. launched a retrospective cohort study among patients with NASH-related cirrhosis at Mayo Clinic Rochester from 2006 to 2015 (7). Among 354 participants with NASHrelated cirrhosis, 30 developed liver cancer during a median period of 47 months. Diabetes was related to an increased HCC risk (adjusted HR, 4.2; 95\% CI: 1.2 to 14.2). In addition, low serum albumin (adjusted HR, 2.1; 95\% CI: 1.5 to 2.9 ) was also positively related to HCC risks. HCC development was not associated with body mass index, hyperlipidemia, and hypertension. They also obtained a registry database of 6,630 adult liver transplant registrants with NASH-related cirrhosis from 2004 to 2017 for external validation. During a median period of 21 months, 291 subjects progressed to HCC. Diabetes was also positively related to HCC risks (adjusted HR, 1.3; 95\% CI: 1.0 to 1.7).

In line with a cohort study linking diabetes to liver cancer in patients who had neither chronic viral hepatitis nor cirrhosis (5), Yang et al. further highlighted the contribution of diabetes to the progression from NASH-related cirrhosis to HCC. However, anti-diabetic medications were not linked to HCC occurrence in this study among participants with diabetes. Nevertheless, to explore the association of anti-diabetic medications with HCC occurrence, restricting the analysis to newly diagnosed diabetes participants on any antidiabetic agents would be more appropriate. A recent nationwide population-based study from 2003 to 2013 in a HCC-endemic area observed that any use of all insulin analogues was no more related to HCC incidence after exclusion of chronic viral hepatitis and concluded that chronic viral hepatitis might amplify the impact of premixed insulin analogues during liver cancer development (8).

A practical concern is that a substantial number of NASHrelated HCCs arise in patients without cirrhosis (9-12). The characteristic features of NASH might appear in patients with early cirrhosis but disappear at late stages of cirrhosis (9). This partially explains why dyslipidemia and obesity were not related to HCC risks among patients with NASH-related cirrhosis, as shown by Yang et al. (7). 
The association between dyslipidemia and the progression of NASH-related cirrhosis to liver cancer might also be affected by the protective effects of lipid-lowering drugs on HCC oncogenesis (13), although many clinicians feared to prescribe lipid-lowering drugs among patients with cirrhosis and led to confounding by contraindication. However, this study did not estimate the association of lipid-lowering drugs with HCC occurrence. Another issue is the potential contribution of occult hepatitis B virus infection to HCC development, but its impact was obscure and difficult to be measured without liver tissues in this study (14). A recent hospital-based analysis of 90 patients with HCC and negative hepatitis B surface antigen reported that $70 \%$ of these patients had occult hepatitis B virus infection (15).

In conclusion, Yang et al. conducted a retrospective cohort study to elucidate a positive association between diabetes and HCC risks in patients with NASH-related cirrhosis. It implies we should arrange liver cancer surveillance for highrisk individuals including the elderly, diabetes patients, and those with a low serum albumin level. Next, clinicians will wonder whether DM prevention or choosing certain antidiabetic medications in NASH-related cirrhosis patients results in reduced HCC risks in the future.

\section{Acknowledgments}

Funding: None.

\section{Footnote}

Conflicts of Interest: Both authors have completed the ICMJE uniform disclosure form (available at https://hbsn. amegroups.com/article/view/10.21037/hbsn.2019.11.03/coif). The authors have no conflicts of interest to declare.

Ethical Statement: The authors are accountable for all aspects of the work in ensuring that questions related to the accuracy or integrity of any part of the work are appropriately investigated and resolved.

Open Access Statement: This is an Open Access article distributed in accordance with the Creative Commons Attribution-NonCommercial-NoDerivs 4.0 International License (CC BY-NC-ND 4.0), which permits the noncommercial replication and distribution of the article with the strict proviso that no changes or edits are made and the original work is properly cited (including links to both the formal publication through the relevant DOI and the license). See: https://creativecommons.org/licenses/by-nc$\mathrm{nd} / 4.0 /$.

\section{References}

1. Massoud O, Charlton M. Nonalcoholic Fatty Liver Disease/Nonalcoholic Steatohepatitis and Hepatocellular Carcinoma. Clin Liver Dis 2018;22:201-11.

2. Estes C, Razavi H, Loomba R, et al. Modeling the epidemic of nonalcoholic fatty liver disease demonstrates an exponential increase in burden of disease. Hepatology 2018;67:123-33.

3. Diehl AM, Day C. Cause, Pathogenesis, and Treatment of Nonalcoholic Steatohepatitis. N Engl J Med 2017;377:2063-72.

4. Wang P, Kang D, Cao W, et al. Diabetes mellitus and risk of hepatocellular carcinoma: a systematic review and metaanalysis. Diabetes Metab Res Rev 2012;28:109-22.

5. Chiang CH, Lee LT, Hung SH, et al. Opposite association between diabetes, dyslipidemia, and hepatocellular carcinoma mortality in the middle-aged and elderly. Hepatology 2014;59:2207-15.

6. Chiang CH, Lu CW, Han HC, et al. The Relationship of Diabetes and Smoking Status to Hepatocellular Carcinoma Mortality. Medicine (Baltimore) 2016;95:e2699.

7. Yang JD, Ahmed F, Mara KC, et al. Diabetes is Associated with Increased Risk of Hepatocellular Carcinoma in Cirrhosis Patients with Nonalcoholic Fatty Liver Disease. Hepatology 2020;71:907-16.

8. Chiang CH, Kuo CS, Lin WW, et al. Chronic Viral Hepatitis Signifies the Association of Premixed Insulin Analogues with Liver Cancer Risks: A Nationwide Population-Based Study. Int J Environ Res Public Health 2019;16. doi: 10.3390/ijerph16122097.

9. Hashimoto E, Tokushige K, Ludwig J. Diagnosis and classification of non-alcoholic fatty liver disease and nonalcoholic steatohepatitis: Current concepts and remaining challenges. Hepatol Res 2015;45:20-8.

10. Mittal S, El-Serag HB, Sada YH, et al. Hepatocellular Carcinoma in the Absence of Cirrhosis in United States Veterans is Associated With Nonalcoholic Fatty Liver Disease. Clin Gastroenterol Hepatol 2016;14:124-31.e1.

11. Tobari M, Hashimoto E, Taniai $M$, et al. The characteristics and risk factors of hepatocellular carcinoma in non-alcoholic fatty liver disease without cirrhosis. J Gastroenterol Hepatol 2020;35:862-69. 
12. Stine JG, Wentworth BJ, Zimmet A, et al. Systematic review with meta-analysis: risk of hepatocellular carcinoma in non-alcoholic steatohepatitis without cirrhosis compared to other liver diseases. Aliment Pharmacol Ther 2018;48:696-703.

13. Nascimbeni F, Pellegrini E, Lugari S, et al. Statins and nonalcoholic fatty liver disease in the era of precision medicine: More friends than foes. Atherosclerosis 2019;284:66-74.

Cite this article as: Chiang CH, Huang KC. Diabetes and hepatocellular carcinoma risks in patients with nonalcoholic steatohepatitis related cirrhosis. HepatoBiliary Surg Nutr 2020;9(3):357-359. doi: 10.21037/hbsn.2019.11.03
14. Chiang CH, Ni YH. Obscure clinical implication of occult hepatitis $\mathrm{B}$ virus infection by perinatal transmission despite prophylaxis with hepatitis B vaccination and HBIG. J Hepatol 2012;57:1401; author reply 1401-2.

15. Wong DK, Cheng SCY, Lung-Yi Mak L, et al. Among Patients with Undetectable Hepatitis B Surface Antigen and Hepatocellular Carcinoma, a High Proportion Has Integration of HBV DNA into Hepatocyte DNA and No Cirrhosis. Clin Gastroenterol Hepatol 2020;18:449-56. 